\title{
An old off-pump coronary artery bypass surgeon's reflections: A retrospective
}

\author{
Gianni D. Angelini, MD, MCh, FRCS, FMed Sci
}

From the Bristol Heart Institute, University of Bristol, Bristol Royal Infirmary, Bristol, United Kingdom.

Received for publication Aug 10, 2018; revisions received Sept 11, 2018; accepted for publication Sept 25, 2018; available ahead of print Nov 2, 2018.

Address for reprints: Gianni D. Angelini, MD, MCh, FRCS, FMed Sci, Level 7, Queen's Building, Bristol Heart Institute, Bristol Royal Infirmary, Marlborough St, Bristol BS2 8HW, United Kingdom (E-mail: g.d.angelini@ bristol.ac.uk).

J Thorac Cardiovasc Surg 2019;157:2274-7

$0022-5223 / \$ 36.00$

Crown Copyright $@ 2018$ Published by Elsevier Inc. on behalf of The American Association for Thoracic Surgery https://doi.org/10.1016/j.jtcvs.2018.09.086

In 2010, at the height of the off-pump coronary artery bypass (OPCAB) surgery controversy, I wrote an editorial for this Journal with one of my trainees, the goal of which was critically to evaluate the status of the technique and its future direction. ${ }^{1}$ We concluded that OPCAB was a safe alternative to on-pump coronary artery bypass (ONCAB) surgery and that, with proper structured training and supervision and in the right environment, OPCAB was a technique "for the many and not the few."

After practicing OPCAB for 25 years, I am reaching the twilight of my surgical career. From this perspective, I reflect on this experience and offer some insights that I hope will be of help to the surgical community, particularly to the young surgeons in training.

\section{EARLY STAGE DEVELOPMENT}

With colleagues, my journey started in 1994, when the aim was to emulate our fellow general surgeons practicing minimally invasive surgery. The goal was to revascularize the left anterior descending coronary artery with the left internal thoracic artery through a left anterior small thoracotomy. ${ }^{2}$ By default, the restricted access led to the surgery being performed on the beating heart. Although I had practiced endoscopic thoracic surgery during my training, I was not accustomed to working in a confined space, and this, combined with the lack of dedicated instruments, sometimes made the surgery impossible.

To increase the proportion of patients to whom a left anterior small thoracotomy could be applied, the hybrid approach was devised with percutaneous coronary intervention with or without stenting. ${ }^{2}$ The simultaneous combination, however, which required using anticoagulation after stenting, was often followed by bleeding from the surgical site. Carrying out percutaneous coronary intervention before surgery did not allow the quality of the surgery to be checked. Percutaneous coronary intervention a few days after surgery did not help in the event of a problem with the left internal thoracic artery-left anterior

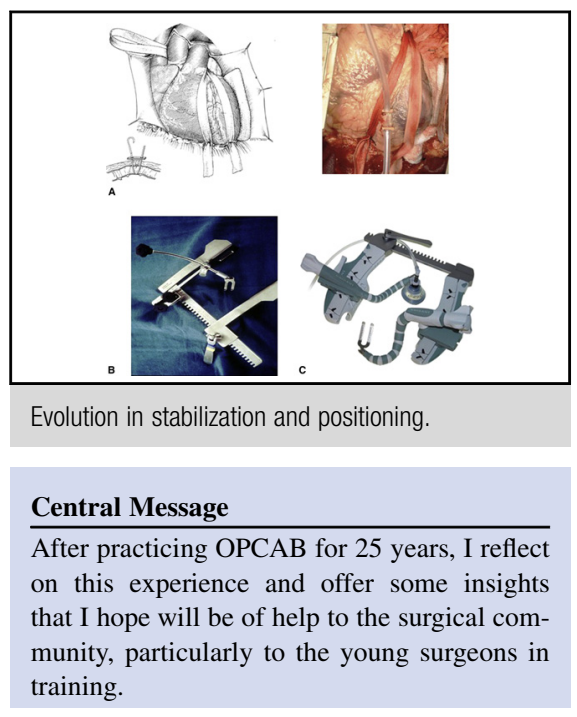

See Commentary on page 2278 .

descending anastomosis. Furthermore, most health service providers charged for 2 separate procedures, with a significant increase in costs.

We soon realized that to revascularize all the ischemic areas of the heart, we had to go back to the experience of surgeons like Buffalo and Benetti in the late 1980s; that is, beating-heart coronary surgery through a median sternotomy. ${ }^{3}$ Ironically, this rejected the quest for a minimally invasive approach and instead prioritized the perceived benefits of avoiding cardiopulmonary bypass (CPB) (Figure 1).

In our institution, a dedicated group including anesthetists, nurses, and surgeons embarked on a structured program that resulted in an increase in OPCAB from $8 \%$ of CABG operations in 1997 to $72 \%$ in 2003 , without any increase in procedural morbidity. In relation to the learning curve, after 100 OPCAB operations, performance was the same or better for the residents in training as for me, the senior consultant. For all surgeons, performance was the same as or better than OPCAB than ONCAB grafting. ${ }^{4}$ Along with many other centers during the early phase, however, we contributed to the main Achilles' heel of OPCAB, "incomplete revascularization." We were in denial, describing vessels that we could not graft because of technical difficulty as being too small or not important. Furthermore, the worldwide excitement of doing pioneering work, and the belief that avoiding CPB was the key to all our 

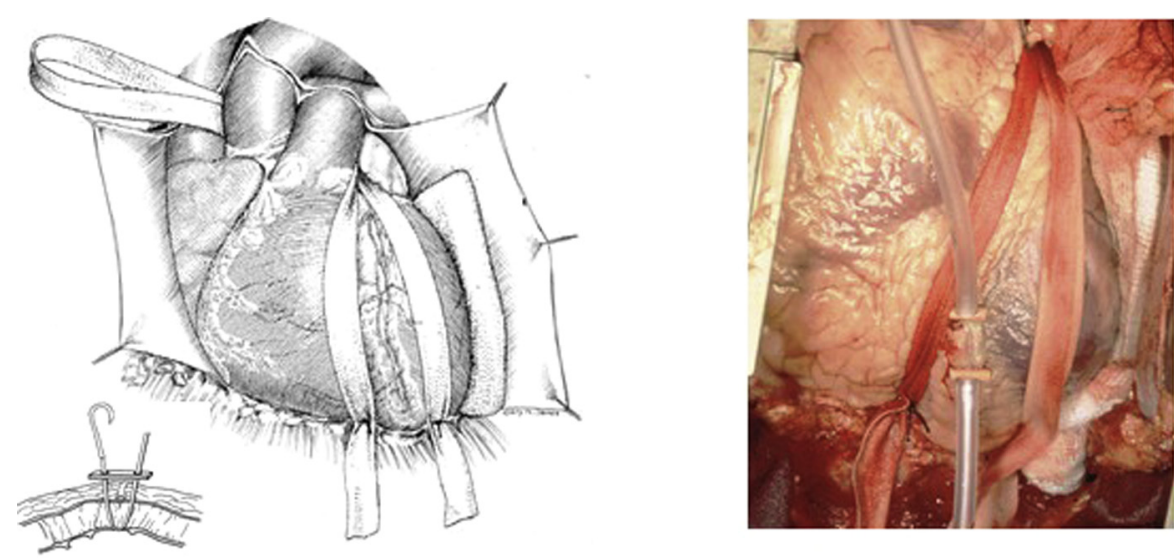

A

B
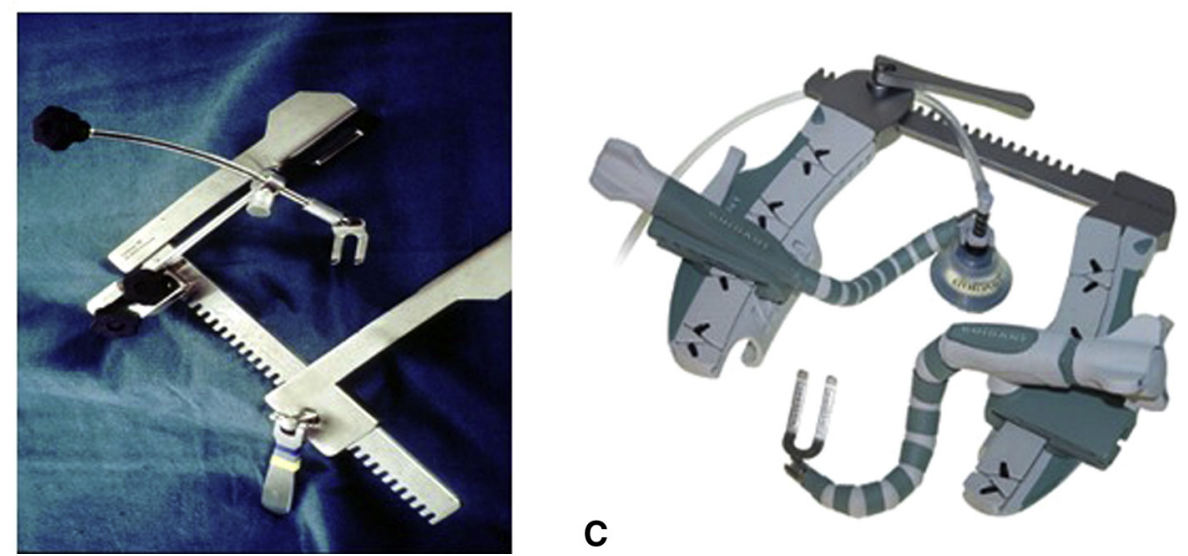

FIGURE 1. Evolution in stabilization and positioning in 25 years of OPCAB surgery. A, Stabilization by means of tapes and snaring of the coronary artery. B, Pressure stabilizer. C, Pressure suction stabilizer and heart positioning device.

problems, resulted in an uncritical and excessive use of the technique.

\section{THE EVIDENCE}

Early single-center studies, both retrospective studies and randomized clinical trials, from units who had enthusiastically adopted OPCAB reported no difference between OPCAB and ONCAB in the 30-day composite outcome of death or complications (reoperation, new mechanical support, cardiac arrest, coma, stroke, or renal failure) or at long term follow-up. .-7 $^{5}$ These studies were followed by numerous randomized trials, meta-analyses, and retrospective case series, which failed to prove a clear superiority of one technique over the other in the short term. In most of these studies, however, there was a reduced incidence of early in hospital complications such as atrial fibrillation, renal and respiratory failure, and requirement for blood products among patients who had OP$\mathrm{CAB}$ compared with those who had ONCAB. . $^{5,6,8-12}$ Conversely, patients who underwent OPCAB generally received a lower average number of grafts, resulting in a higher incidence of incomplete revascularization and need for repeat revascularization. This is likely to have affected long-term survival, although contradictory results have been reported. .,11-15 $^{-15}$

These findings led to the question: Should OPCAB be performed by a dedicated team available in every institution, as with mitral valve repair and major aortic surgery, or should it be part of routine clinical practice in the armamentarium of every surgeon?

\section{OPCAB: FOR THE MANY OR THE FEW?}

$\mathrm{OPCAB}$ is technically demanding and a more difficult technique to master than ONCAB. In my opinion (although this may sound controversial and immodest) it requires more than average surgical dexterity. In my career, I have seen trainees and senior surgeons struggling to perform a coronary anastomosis on $\mathrm{CPB}$ and on an arrested heart. OPCAB also requires a different state of mind, because the operator does not have the CPB machine to fall back on. A good OPCAB surgeon is one who knows when it is 
time to convert to $\mathrm{ONCAB}$, giving plenty of warning to the perfusion team, and well before the hemodynamic status deteriorates and the heart arrests. A similar decision should be taken with no shame when complete revascularization cannot be achieved with OPCAB. Unplanned conversion dramatically increases the risk of perioperative complications, hospital cost, and mortality. ${ }^{16,17}$

The role of experience is illustrated by the broad, simple index of the rate of conversion. In the Society of Thoracic Surgeons database, the conversion rate for 196,000 patients was $5.5 \%$, of which $50 \%$ were elective. ${ }^{18}$ In the Randomized On/Off Bypass (ROOBY) trial, ${ }^{11}$ the rate of conversion was $12.5 \%$ (surgeons took part regardless of their experience, and $55 \%$ of the procedures were performed by surgeons in training). Even in the CABG Off or On Pump Revascularization Study (CORONARY) trial, ${ }^{10}$ in which surgeons were required to have performed 100 OPCAB procedures before been allowed to recruit, the conversion rate was $7.9 \%$. In a post hoc analysis of the Arterial Revascularization Trial (ART) including 1260 patients undergoing OPCAB and 1700 undergoing ONCAB, "sporadic" OP$\mathrm{CAB}$ surgeons (1-5 procedures) had a higher rate of conversion $(12.9 \%)$ than "high-volume" OPCAB surgeons, and a higher operative mortality $(4.8 \%)$ when compared with ONCAB despite a similar distribution of risk factors. OPCAB performed by 3 high-volume OPCAB surgeons (>60 procedures) showed very low conversion rate $(1 \%)$, and the 5-year mortality of OPCAB performed by 95 "OPCAB-only" surgeons (outside the trial) was comparable to ONCAB mortality. ${ }^{19}$

These observations highlight that one of the reasons for the conflicting results reported in the literature may simply be comparing a long-term, well-established technique, $\mathrm{ON}$ $\mathrm{CAB}$ (part of any trainee curriculum and surgeon main practice), with a relatively new procedure, OPCAB, carried out by enthusiastic but insufficiently experienced or "occasional" surgeons.

Acquiring proficiency in OPCAB requires a learning curve and experienced trainers in a dedicated institution. Except for a few dedicated units that offer fellowship training, to the best of my knowledge there are no national societies that have included OPCAB in the training curriculum. The perception that success with the technique is limited to more proficient surgeons, and a fear of deleterious patient outcomes, especially during the learning curve, is also deterring young surgeons from adopting the technique. This is particularly relevant in the United Kingdom, where the results of cardiac surgery units and individual surgeons are published and made available to the public. Furthermore, the fear of naming and shaming and the potential of negative repercussions on private practice are also important considerations.

The controversy about routine use of OPCAB is not dissimilar from that regarding arterial revascularization in
CABG; a technique embraced by a few dedicated surgeons that has failed to be adopted into routine clinical practice. Is this as often advocated because of lack of clear evidence of superiority, or simply because it is a technically demanding technique with all the same potential problems described for OPCAB?

Currently, in the United States and Europe, OPCAB is used in roughly $20 \%$ to $25 \%$ of patients, whereas in India and Japan, it is the most common strategy. It has been suggested that in India uptake has been driven by economic considerations, whereas in Japan it may be because surgeons have traditionally embraced the most advanced techniques, such as total arterial coronary revascularization. A more hierarchic structure may also play a role in deciding what surgical strategy a unit will adopt, contrary to the United Kingdom, where all senior surgeons are to a degree their own masters.

\section{CONCLUSIONS}

When performed by experienced surgeons in centers with the right infrastructure, OPCAB is a safe alternative to ONCAB, regardless of the patients' risk profile, and it is associated with reduced early hospital complications and similar long-term outcomes. OPCAB should always aim to achieve complete myocardial revascularization and be converted to ONCAB if for any technical reason this cannot be achieved. There is a body of evidence in the literature linking poor outcome in OPCAB to surgeons' limited experience and low-volume centers. OPCAB is a challenging technique with a steep learning curve. To master the learning curve, a team approach is of paramount importance. This would be helped by the introduction of specialization in the training curriculum, as is the case for mitral valve repair and major aortic surgery. Established, recognized OPCAB units should be identified to provide training fellowships. Recognized OPCAB teams could then select trainees with the right dexterity and attitude to facilitate the uptake of OPCAB.

At present, OPCAB surgery should be a specialized practice for the few, with the potential to become for the many given the right commitment to training.

\section{Conflict of Interest Statement}

Author has nothing to disclose with regard to commercial support.

\section{References}

1. Patel NN, Angelini GD. Off-pump coronary artery bypass grafting: for the many or the few? J Thorac Cardiovasc Surg. 2010;140:951-3.e1.

2. Angelini GD, Wilde P, Salerno TA, Bosco G, Calafiore AM. Integrated left small thoracotomy and angioplasty for multivessel coronary artery revascularisation. Lancet. 1996:347:757-8.

3. Buffolo E, Andrade JC, Succi J, Leão LE, Gallucci C. Direct myocardial revascularization without cardiopulmonary bypass. Thorac Cardiovasc Surg. 1985;33: 26-9. 
4. Caputo M, Reeves BC, Rogers CA, Ascione R, Angelini GD. Monitoring the performance of residents during training in off-pump coronary surgery. $J$ Thorac Cardiovasc Surg. 2004;128:907-15.

5. Mack M, Bachand D, Acuff T, Edgerton J, Prince S, Dewey T, et al. Improved outcomes in coronary artery bypass grafting with beating-heart techniques. $J$ Thorac Cardiovasc Surg. 2002;124:598-607.

6. Angelini GD, Taylor FC, Reeves BC, Ascione R. Early and midterm outcome after off-pump and on-pump surgery in Beating Heart Against Cardioplegic Arrest Studies (BHACAS 1 and 2): a pooled analysis of two randomised controlled trials. Lancet. 2002:359:1194-9.

7. Angelini GD, Culliford L, Smith DK, Hamilton MC, Murphy GJ, Ascione R, et al. Effects of on- and off-pump coronary artery surgery on graft patency, survival and health-related quality of life: long-term follow-up of 2 randomized controlled trials. J Thorac Cardiovasc Surg. 2009;137:295-303.

8. Wijeysundera DN, Beattie WS, Djaiani G, Rao V, Borger MA, Karkouti K, et al. Off-pump coronary artery surgery for reducing mortality and morbidity: metaanalysis of randomized and observational studies. J Am Coll Cardiol. 2005;46; 872-82.

9. Cheng DC, Bainbridge D, Martin JE, Novick RJ, Evidence-Based Perioperative Clinical Outcomes Research Group. Does off-pump coronary artery bypass reduce mortality, morbidity, and resource utilization when compared with conventional coronary artery bypass? A meta-analysis of randomized trials. Anesthesiology. 2005; 102:188-203.

10. Lamy A, Devereaux PJ, Prabhakaran D, Taggart DP, Hu S, Paolasso E, et al; CORONARY Investigators. Off-pump or on-pump coronary-artery bypass grafting at 30 days. $N$ Engl J Med. 2012;366:1489-97.

11. Shroyer AL, Grover FL, Hattler B, Collins JF, McDonald GO, Kozora E, et al; Veterans Affairs Randomized On/Off Bypass (ROOBY) Study Group. On- pump versus off-pump coronary-artery bypass surgery. N Engl J Med. 2009; 361:1827-37.

12. Diegeler A, Börgermann J, Kappert U, Breuer M, Böning A, Ursulescu A, et al GOPCABE Study Group. Off-pump versus on-pump coronary-artery bypass grafting in elderly patients. N Engl J Med. 2013;368:1189-98.

13. Lamy A, Devereaux PJ, Prabhakaran D, Taggart DP, Hu S, Straka Z, et al; COR ONARY Investigators. Five-year outcomes after off-pump or on-pump coronaryartery bypass grafting. $N$ Engl J Med. 2016;375:2359-68.

14. Shroyer AL, Hattler B, Wagner TH, Collins JF, Baltz JH, Quin JA, et al; Veterans Affairs ROOBY-FS Group. Five-year outcomes after on-pump and off-pump coronary-artery bypass. $N$ Engl J Med. 2017;377:623-32.

15. Filardo G, Hamman BL, da Graca B, Sass DM, Machala NJ, Ismail S, et al. Efficacy and effectiveness of on- versus off-pump coronary artery bypass grafting: a meta-analysis of mortality and survival. J Thorac Cardiovasc Surg. 2018;155: 172-9.e5.

16. Li Z, Amsterdam EA, Danielsen B, Hoegh H, Young JN, Armstrong EJ. Intraoperative conversion from off-pump to on-pump coronary artery bypass is associated with increased 30-day hospital readmission. Ann Thorac Surg. 2014;98:16-22.

17. Reeves BC, Ascione R, Caputo M, Angelini GD. Morbidity and mortality following acute conversion from off-pump to on-pump coronary surgery. Eur J Cardiothorac Surg. 2006;29:941-7.

18. Keeling B, Thourani V, Aliawadi G, Kim S, Cyr D, Badhwar V, et al. Conversion from off-pump coronary artery bypass grafting to on-pump coronary artery bypass grafting. Ann Thorac Surg. 2017;104:1267-74.

19. Benedetto U, Altman DG, Gerry S, Gray A, Lees B, Flather M, et al; Arterial Revascularization Trial Investigators. Off-pump versus on-pump coronary artery bypass grafting: insights from the Arterial Revascularization Trial. J Thorac Car diovasc Surg. 2018;155:1545-53.e7. 